\title{
WHAT MAKES INTRODUCTORY PHYSICS DIFFICULT?
}

\author{
Untung Nugroho Harwanto \\ Program Studi Teknik Kimia, Universitas Pamulang \\ untung.nugroho@unpam.ac.id
}

\begin{abstract}
The purpose of this study was to make an investigation what makes physics difficult. Students from different islands in Indonesia who were taking a preparation course in South Tangerang were taken into account of survey. A yes-no answer questionnaire was prepared in order to get the students perception toward physics. The questionnaire was given to approximately 115 students in the middle of the semester. The students were asked to full fill a questionnaire through what makes introductory physics difficult. We found that factor related to the nature of physics is taking part as the maximum percentage on the reason why physics considered as a difficult subject. But factor related to the courses is taking part as the minimum percentage on the reason why physics considered as a difficult subject. The female and male students mostly agreed that the factor related to the nature of physics and took more than fifty percent. Lack of physics background, lack of previous experience and working only assigned problem have the high percentage as the part of student controlled factor. Physics is cumulative subject and physics required good mathematics both are taking high percentage related to the nature of physics.
\end{abstract}

Keywords: introductory physics, difficult, physics course, mahtematical background

\section{INTRODUCTION}

\subsection{General Overview of the Research Problem}

According to the students, physics is a difficult subject especially for the "average" students (Sobel, 2009). Introductory physics is difficult for many students (Ornek, Robinson and Haugan, 2008). Physics is unlike any other subject you will encounter (Aikenhead,2003). It requires a unique approach; concepts and practice. Physics introduction is a rapidly paced class. Missing even one lecture will set you back. Playing catch-up in physics usually results in the student not fully understanding concepts. Get ahead and stay ahead. Learning physics is comparable to learning a new language. If you don't put in the time, it's difficult to succeed.

Math is the language used to communicate physics. Lasry, Finkelstein and Mazur (2009) fully agreed that physics without any enough mathematicalbackground 
is an incomplete subject. However, it was equally incomplete when math without any physics concepts.

Students' understanding of the course is depending on their view about a course. Why some students failed on their physics course is because their view of "physics is a difficult subject". Angell, Guttersrud, Henriksen \& Isnes (2004) explored the students' view about physics. On their research, they found that physics seem so difficult because the students have to deal with very colorful representations such as graphs, equation, diagrams, experiments and conceptual understanding at the same time. And also the students have to able to make conversion among them at the same time. As an example, students sometimes need to be able to convertmathematical formulas into physical explanation and sometimes they have to be able to transform from mathematical representation to physical explanation.

According to Redish (1994), they explore what make students judge physics as a difficult course.Physics is a discipline requires learners to be able to apply a variety of methods of learning and to convert from numbers to graphs, equation to diagrams and others.

Angell at al. (2004) also found that some students viewed physics to be boring and irrelevant course. They, however, showed that it was students that did not study physics that felt this way; those that were taking physics classes actually claimed it was relevant and interesting. The major obstacle to enrolment in physics may be getting students through the door of a physics classroom; once there, perhaps the students' negative perceptions can change. Alternatively, it may demonstrate that only those students who have positive preconceptions of physics are enrolling in physics.

\subsection{Objectives of the Study}

This is a thesis research on what makes physics difficult according to the Indonesian students specially the students who live in remote area.

\subsection{Significance of the Study}

Actually there are several points to clarify the significance of this research. First of all, the exploration of one question on what makes physics difficult? Physics is often considered as a difficult lesson, an observation of exploring on what makes physics difficult is the first important question that should be answered before. A questionnaire was developed to find out the students' opinion on why physics is difficult for them? From the collected data of this questionnaire, the researcher can easily understand the fundamental reason of the students' problem on physics learning. The goal of this research will be useful if the product can solve the fundamental problem of students when they are learning physics. 


\section{RESEARCH METHODOLOGY}

In this chapter, there will be presented more detail information about design of the study, sample and population, variables, instruments and validity.

\subsection{Design of the Study}

We collected a yes-no answer questionnaire to approximately 115 students in the middle of the semester to the university students who are studying in South Tangerang. The students were asked to full fill a questionnaire through what makes introductory physics difficult.

In this study, the sample consists of 115 physics students. The students were coming from different part of Indonesia. They are living in the different islands, such as: Sumatra, Kalimantan, Papua and West Papua. This research conducted 37 Sumatran students, 10 Kalimantan students, 36 Papuan students and 32 West Papuan students. All the students are studying in Surya School of Education.

\subsection{Population and Sample}

The target population of the initial survey on exploring the students' perception of what makes physics difficult is all the urban physics students who are taking a preparation class in South Tangerang. The sample was drawn from 115 of approximately 480 physics students who are studying in South Tangerang that comprise the accessible population. The treatments were randomly assigned. The sample was consisted of 115 students who are coming from different islands in Indonesia (37 Sumatran students, 10 Kalimantan students, 36 Papuan students and 32 West Papua students).

Table 1. Distributions of participants toward their origin

\begin{tabular}{cc}
\hline Origin & Number of participant \\
\hline Sumatra & 37 \\
Kalimantan & 10 \\
Papua & 36 \\
West Papua & 32 \\
\hline
\end{tabular}

\section{RESULT}

In order to see how the students' view on what makes physics difficult were explored from a form questionnaire. In other words, research question on what makes physics difficult was assessed through this instrument. The checklist was modified from the questionnaire that had been developed by the Ornek, Robinson and Haugan, (2008). There were three factors in the questionnaire. Each factor consists of 10 item questions. 
Each alternative in the checklist anwer was divided into agree and disagree. The number of items in each factor, and students' averages on each factor is given in Table 2.

Table 2. The Average Score of Each Factor.

\begin{tabular}{lc}
\hline Factor & Average scores (\%) who agree \\
\hline Factor related to the students & 68,71 \\
Factor related to the courses & 48,92 \\
Factor related to the nature of physics & 73,89 \\
\hline
\end{tabular}

Table 2 indicates that factor related to the nature of physics is taking part as the maximum percentage on the reason why physics considered as a difficult subject. The factor related to the courses is taking part as the minimum percentage on the reason why physics considered as a difficult subject. It means that students have no problem with the course activity but it will be problem when they faced with physics subject. What is remarkable is that students think much problem when they hear or listen about physics word.

The average of each origin and gender on the questionnaire of what makes physics difficult and their average score on each factor are given in Table 3 and Table 4.

Table 3. TheAverage Score of Each Factor Toward the Students' Origin

\begin{tabular}{lcccc}
\hline \multirow{2}{*}{ Factors } & \multicolumn{4}{c}{ Origin } \\
\cline { 2 - 5 } & $\begin{array}{c}\text { Sumatra } \\
(\%)\end{array}$ & $\begin{array}{c}\text { Kalimantan } \\
(\%)\end{array}$ & $\begin{array}{c}\text { Papua } \\
(\%)\end{array}$ & $\begin{array}{c}\text { WestPapua } \\
(\%)\end{array}$ \\
\hline Factor related to the students & 55,3 & 57,0 & 49,3 & 46,7 \\
Factor related to the courses & 39,2 & 36,6 & 36,7 & 31,9 \\
Factor related to the nature of physics & 51,8 & 60,0 & 54,9 & 56,2 \\
\hline
\end{tabular}

According to the table 3 above, it showed that all Sumatran, Kalimantan, Papua and West Papua students have less than $40 \%$ said that physics was difficult because of the factor related to the course. More than fifty percent of the Sumatran and Kalimantan students agreed that the students controlled factor have an important impact on makes physics become difficult. But it just takes under fifty percent for the Papuan and West Papua students agreed. From the factor related to the nature of physics, all the origins have number more than fifty percent. So we can conclude that all the Sumatran, Kalimantan, Papua and West Papuaall agree that the factor related to the nature of physics have a dominant impact on making physics become difficult. 
Table 4. The average score of each factor of the questionnaire what makes physics difficult toward the students' gender

\begin{tabular}{lcc}
\hline \multirow{2}{*}{ Factors } & \multicolumn{2}{c}{ Gender } \\
\cline { 2 - 3 } & Male (\%) & Female (\%) \\
\hline Factor related to the students & 56,0 & 48,2 \\
Factor related to the courses & 38,0 & 38,1 \\
Factor related to the nature of physics & 59,4 & 52,0 \\
\hline
\end{tabular}

From the table 4 above, the students' gender view on what makes physics difficult can be explored more detail. The female and male students mostly agreed that the factor related to the nature of physics and it took more than fifty percent. But they mostly didn't agree that the course controlled factor make physics difficult because it just takes not more than forty percent. It was interesting when how the factor related to the students regarding to the gender. It was different between male and female students. More than fifty percent of the male students agree that students-related factor makes physics difficult but not more than fifty percent of female students agree.

It was a same view on male and female students on the three factors of the reason on why physics difficult. The female and male students viewed that the factor related to the nature of physics is the most influenced factor among the three factors on why physics difficult. And the factor related to the course took the least reason on why physics difficult.

We can separate the items in Table 5 extremely into two groups. The first group is the item that has a high percentage of the students who mostly agree and the second group is the item that has a low percentage of the students who agree. 
Table 5. The Percentage of Each Item Through Students Controlled Factor

\begin{tabular}{ll}
\hline Lack of motivation and interest & $\begin{array}{c}\text { Percentage of } \\
\text { students }\end{array}$ \\
\hline Not studying more & 57 \\
\hline Not reading the textbook & 49 \\
\hline Not completing CHIP assignment & 46 \\
\hline Not doing practice many problems & 21 \\
\hline Working only assigned problems & 70 \\
\hline Not doing homework & 81 \\
\hline Lack of previous experience & 21 \\
\hline Lack of physics background & 81 \\
\hline Lack of higher level mathematics & 89 \\
\hline
\end{tabular}

Lack of physics background, lack of previous experience and working only assigned problem are collected as the first group who has high percentage. From the table 4.4 showed that each part of the first group took more than $80 \%$. The student agreed that lack of physics background (89\%), lack of previous experience $(81 \%)$ and working only assigned problem $(81 \%)$ are important issues of making physics difficult when viewed from the students. The students must be able to work more than just solve the assigned problems, do one more experience in order to have better experience and read detaily the physical concept to enhance their physics background.

The second group consists of not completing CHIP (Computational Homework in Physics) assignment and not doing homework. This group took not more than $25 \%$. So the students agreed that not doing homework and not completing CHIP assignment both are not have a big influence on making physics difficult. 
Table 6. The Percentage of Each Item Through Course Controlled Factor

\begin{tabular}{lc}
\hline & Percent of students \\
\hline Too much work & 56 \\
\hline Hard CHIP homework & 39 \\
\hline $\begin{array}{l}\text { Lack of consistency between the } \\
\text { lab/tutorial/lecture and homework }\end{array}$ & 23 \\
\hline $\begin{array}{l}\text { Textbooks, lectures, CHIP homework questions } \\
\text { are too complicated }\end{array}$ & 31 \\
\hline Tutorial sections are not useful & 16 \\
\hline Being picky on grading & 40 \\
\hline $\begin{array}{l}\text { Not enough examples, real life applications, and } \\
\text { problem solving especially conceptual } \\
\text { questions in class }\end{array}$ & 54 \\
\hline $\begin{array}{l}\text { Hard questions on the exams and were not } \\
\text { related to what solved in the class }\end{array}$ & 19 \\
\hline Poor professors & 41 \\
\hline Poor TAs & 43 \\
\hline
\end{tabular}

From table 6 there is no high percentage related to the course controlled factor. Each item in the course controlled factor takes part not more than $56 \%$. Only two items have more than fifty percent, such as too much work (56\%) and not enough examples, real life application and problem solving especially conceptual question in class (54\%). Students think that physics is a subject who pushsthem to do much work. They need to get more information on relationship between conceptual theory in the class and real life also they have to work hardly in the course to be successful in physics. Some items, such as tutorial sections are not useful and hard questions on the exam and were not related to what solved in the class both are have not more than twenty percent. 
Table 7. The Percentage of Each Item Through Factor Related to the Nature of Physics.

\begin{tabular}{ll}
\hline & Percent of students \\
\hline $\begin{array}{l}\text { Physics is cumulative. If you miss one } \\
\text { concept, it is hard to grasp the next one }\end{array}$ & 97 \\
\hline Physics is very difficult subject & 29 \\
\hline There is too much material to learn & 59 \\
\hline Physics is very abstract & 42 \\
\hline Physics requires good mathematics & 95 \\
\hline Physics has too much theory & 39 \\
\hline $\begin{array}{l}\text { Physics has too many formulas to be } \\
\text { learned }\end{array}$ & 48 \\
\hline Physics has too many laws and rules & 52 \\
\hline Physics is not interesting enough & 7 \\
\hline $\begin{array}{l}\text { Physics cannot be learned without } \\
\text { mathematics background }\end{array}$ & 79 \\
\hline
\end{tabular}

We candevide the items in table 4.6 into two separately groups. The first group is being extremely high percentage and the second one isbeing extremely low percentage. The first group consists of physics is cumulative (97\%) and physics required good mathematics $(95 \%)$. Each item in the first group takes more than ninety percent of the students who agree that it becomes problem on making physics difficult. The students agree that physics is an accumulative subject and it requires good mathematics. The students must be able to work continously in order to get easy to grasp the next concept and also they have to be able to work better in mathematics subject in order to get better physical calculation. If they have no enough mathematics background, it will be problem in learning more on physics subject. And also if they miss one concept, it is difficult to follow and understand the next one.

Physics is not interesting enough is the only one of the second group who has extremely low percentage. It means students didn't think that physics is not interesting enough. Physics is interesting enough but they didn't know how to work better with physics.

\section{CONCLUSION AND RECOMMENDATIONS}

The purpose of this study was to make an investigation for finding out on what students believe makes physics difficult. Students from different island in Indonesia who are taking a preparation course in South Tangerang was taken into account of survey. 
From the result, we found that students from different part of Indonesia have no much different perceptions about what make physics difficult. Students think closely in terms of their problem toward physics learning. This study has shown that basically the lack of mathematics background becomes the most important reason on physics difficult. We need to provide our students with a scenario in which one model is supported by simple mathematics so that the students can be easier to understand the introductory physics. Consequently, although introductory physics is difficult, we can convince our students with arguments that are closely linked to mathematical evidence.

Even though we cannot generalize our findings to all physics courses because every physics course might be different, we believe the findings about how the students think about physics and difficulties in physics can be useful to faculty of physics courses in other universities. We recommend that faculty members try a similar survey for their classes because it would give them an opportunity to see that course in the way their students perceive it.

According to many students, introductory physics is difficult (Ornek, Robinson and Haugan, 2008). This study shows that learning physics is difficult for many reasons. Students' views about a course influence their understanding and learning of that course. Many students think and say, "Physics is difficult". According to Angell, Guttersrud, Henriksen and Isnes (2004) on the research of the views of high school students and physics teachers about physics. They found that students find physics difficult because they have to contend with different representations such as experiments, formulas and calculations, graphs, and conceptual explanations at the same time. Physics requires the ability to use algebra and geometry and to go from the specific to the general and back Redish (1994). According to Carter and Brickhouse (1989) students, faculty and teaching assistants will live in different World and it will be difficult to communicate because they speak different languages.

This study has shown that basically the the lack of mathematics background become the most important reason on physics difficult. We need to provide our students with a scenario in which one model is supported by simple mathematics. So that the students can be easier to understand the introductory physics. Consequently, although introductory physics is difficult, we can convince our students with arguments that are closely linked to mathematical evidence.

The research of what makes physics difficult provides one more valuables information that can be used by educational policy makers or teachers on designing an appropriate curriculum, preparing course materials and choosing the learning method. On the basis of the findings from this study and the literatures reviewed, it is recommended that every physics course is never be same and always controlled by different condition and culture so it is mostly impossible to generalize our research findings to all physics courses. But the findings about difficulties in physics course can be useful to educational policy makes to decide an alternative solution on giving better teaching model especially in physics learning. We recommend to all educational policy makers, teachers or faculty members to make a similar research in order to give them an opportunity to understand better the students' problem on physics learning. 


\section{REFERENCES}

Aikenhead, G. S., Chemistry and physics instruction: Integration, ideologies, and choices, Chemical Education: Research and Practice,4(2), 115-130, 2003.

Angell, C., Guttersrud, Q., Henriksen, E. K. \& Isnes, A., Physics: Frightful, but fun, Pupils' and teachers' views of physics and physics teaching [Electronic version]. Science Education, 88, 683-706, 2004.

Carter, S. C., \& Brickhouse, N. W., What makes chemistry difficult? Alternate Perceptions. Journal of Chemical Education, 66, 223-225, 2005.

Lasry, N., Finkelstein, N., Mazur, E., Are Most People too Dumb for Physics. The Physics Teacher, 47, 2009.

Ornek, F., Robinson, W. R. \&Haugan M. P.,What Makes Physics Difficult?International Journal of Environmental and Science Education, 3(1), 30-34, 2008.

Redish, E. F., The implications of cognitive studies for teaching physics. American Journal of Physics, 62, 796-803, 1994.

Sobel, M., Physics for the non-scientist: A middle way, Physics Teaching, 47, 346-349, 2009. 